\title{
A PARTICIPAÇÃO DO PAI COMO ACOMPANHANTE DA MULHER NO PARTO ${ }^{1}$
}

\author{
Fernanda Rosa Indriunas Perdomini², Ana Lúcia de Lourenzi Bonilha ${ }^{3}$
}

\footnotetext{
${ }^{1}$ Recorte da dissertação - A participação do pai como acompanhante da mulher no processo de nascimento, defendida no Programa de Pós-Graduação em Enfermagem, da Escola de Enfermagem da Universidade Federal do Rio Grande do Sul (UFRGS), 2010.

${ }^{2}$ Mestre em Enfermagem. Enfermeira do Hospital de Clínicas de Porto Alegre. Rio Grande do Sul, Brasil. E-mail: fe.indri@ gmail.com

${ }^{3}$ Doutora em Enfermagem. Professora Associado da UFRGS. Rio Grande do Sul, Brasil. E-mail: bonilha.ana@gmail.com
}

\begin{abstract}
RESUMO: Este é um estudo qualitativo, tipo estudo de caso, cujo objetivo foi conhecer a participação do pai, como acompanhante da mulher durante o parto. Fizeram parte 24 pais que estiveram presentes durante o trabalho de parto e parto de suas companheiras, no Hospital de Clínicas de Porto Alegre-RS. As informações, coletadas através de observação participante e entrevista semiestruturada, foram submetidas à análise de conteúdo do tipo temática. O tema encontrado foi a experiência de ser acompanhante no que diz respeito à presença e ao significado da experiência de vivenciar o nascimento do filho. Os achados do estudo revelaram que os pais entendem que estar presente, dar carinho e usar palavras de apoio faz parte do papel de ser acompanhante. Os pais acreditam que a experiência de vivenciar o nascimento do seu filho, independente do número de nascimentos já acompanhados por eles, é uma experiência única, um momento inexplicável.
\end{abstract}

DESCRITORES: Humanização da assistência. Parto humanizado. Relações pai-filho.

\section{FATHER PARTICIPATION AS A COMPANION TO DELIVERING WOMEN}

\begin{abstract}
The objective of this qualitative case study was to determine paternal participation as a companion to women during delivery. There were 24 fathers present during the labor and delivery processes accompanying their wives at the Porto Alegre, RS, Brazil, Clinical Hospital (Hospital de Clínicas). Information was obtained through participative observation and semi-structured interviews and was then submitted to content analysis (thematic type). The theme found was the experience of being a companion which regards the presence and the meaning of living the child's birth. The findings of this study showed that the fathers involved understood that being present, caring, and saying supportive words is part of their role as a companion during this moment. The fathers believe that the experience of living their child's birth, independent from the number of births which they may have already been experienced, is a unique event and an inexplicable moment.
\end{abstract}

DESCRIPTORS: Humanization of assistance. Humanizing delivery. Father-child relationships.

\section{LA PARTICIPACIÓN DEL PADRE COMO ACOMPAÑANTE DE LA MUJER DURANTE EL PARTO}

RESUMEN: Se trata de un estudio de caso, de carácter cualitativo, con el objetivo de conocer la participación del padre como acompañante de la mujer durante el parto. Participaron del estudio veinticuatro padres que estuvieron presentes durante el trabajo de parto y en el parto de sus compañeras, en el Hospital de Clínicas de Porto Alegre-RS. Las informaciones, colectadas por medio de observación participante y entrevista semi-estructurada, se examinaron a través del análisis de contenido temático. El tema encontrado: la experiencia de ser acompañante, se refiere a la presencia y el significado de la experiencia de vivir el nacimiento del hijo. Los hallazgos del estudio revelaron que los padres entienden que estar presente, dar cariño y usar palabras de apoyo hacen parte del rol de ser acompañante en ese momento. Los padres creen que la experiencia de vivir el nacimiento del su hijo, independiente del número de nacimientos ya acompañados por ellos, es una experiencia única, un momento inexplicable.

DESCRIPTORES: Humanización de la atención. Parto humanizado. Relaciones padre e hijo. 


\section{INTRODUÇÃO}

A gestação mobiliza uma explosão de sentimentos no casal, assim como gera uma ansiedade com a espera e a preparação para o nascimento do bebê. Nesse momento, há um período de transição no qual os pais se preparam para os novos papéis diante da chegada do bebê e para tudo o que isso irá exigir deles. Dessa forma, eles se envolvem de forma física e emocional com o período gestacional. ${ }^{1}$

A vivência do parto é considerada uma experiência única na vida do homem e da mulher. ${ }^{2}$ Devido a esse fator, é necessário considerar o momento do parto como um acontecimento intenso para o casal. Tanto um quanto o outro podem vivenciar múltiplos sentimentos com a chegada do novo integrante da família, o que torna necessário que a equipe de saúde esteja preparada para acolher e proporcionar ao casal um momento agradável, tranquilo, contribuindo para que esta seja uma experiência positiva para ambos.

Nesse sentido é necessário que as instituições hospitalares devam garantir o cumprimento da Lei $\mathrm{n}^{\mathrm{o}} 11.108$, promulgada em 7 de abril de 2005, que assegura a presença do acompanhante de escolha da mulher durante o processo do nascimento. ${ }^{3}$ Assim a mulher poderá optar em ter um acompanhante com o qual ela possua vínculo para estar ao seu lado seja no período de trabalho de parto, parto ou pós-parto imediato.

O pai do bebê pode ser considerado o acompanhante ideal para a mulher no processo de parturição, devido a fatores como a formação de vínculo e a representação de laços de família, uma vez que, ao acompanhar o nascimento do filho, ele estaria afirmando sua paternidade, assim como valorizando seu papel. ${ }^{4}$ Estudos têm comprovado os benefícios da permanência do pai como acompanhante durante o processo de parturição. ${ }^{4-8}$ Além disso, as mulheres que foram acompanhadas pelo pai do recém-nascido durante o processo de nascimento, relataram o quanto é importante ter uma pessoa conhecida para proporcionar carinho, cuidado e atenção. ${ }^{9}$

Nesse sentido, não se pode negar ao pai vivenciar um dos momentos mais importantes da vida do ser humano: o nascimento. Este significa o ponto máximo da gestação, visto que o bebê torna-se real, podendo ser pego nos braços, o que proporciona emoções marcantes. ${ }^{10}$

A presença do pai na cena do parto, acompanhando a evolução do trabalho de parto e parto da mulher, apoiando-a constantemente, tem consequências no desfecho do nascimento do bebê: efeitos positivos na construção do vínculo entre o pai e o recém nascido, assim como, estímulo à mulher no momento de parir, podendo dessa for$\mathrm{ma}$, diminuir intercorrências durante o processo de nascimento o qual certamente será lembrado de forma marcante na vida do casal.

É preciso pensar sobre a inserção do pai e de seu contexto familiar na cena do parto e pós-parto, uma vez que o nascimento do bebê influência a formação de uma nova família, permeando uma diversidade de arranjos. ${ }^{11}$

Assim, esse estudo teve como objetivo conhecer a participação do pai como acompanhante da mulher durante o trabalho de parto e parto.

\section{METODOLOGIA}

Trata-se de um estudo qualitativo, ${ }^{12}$ do tipo estudo de caso. ${ }^{13} \mathrm{~A}$ abordagem qualitativa foi escolhida por ser a mais adequada e estabelecer interação com a realidade estudada. ${ }^{12}$

O estudo foi desenvolvido no Centro Obstétrico (CO) do Hospital de Clínicas de Porto Alegre (HCPA) que desde a implantação da Lei n ${ }^{\circ} 11.108$ de 7 de abril de 2005, está garantida a presença do acompanhante de escolha da mulher, durante o trabalho de parto e parto, seja ele vaginal ou cesariana, independente da vontade dos profissionais de saúde. Além disso, no CO deste hospital universitário, estão sendo adotadas novas formas de atendimento à mulher durante o trabalho de parto e parto e ao seu familiar. Entre elas está o manejo da dor durante o trabalho de parto, com a utilização de métodos não-farmacológicos, como a bola suíça, o cavalinho, a massagem, e também, o atendimento ao grupo de gestantes com seus companheiros que, durante o pré-natal, realizado nessa instituição e em outros locais, visitam o CO, para que o casal possa conhecer essa área física e sua dinâmica.

Os participantes desse estudo foram 24 pais que estiveram presentes durante o trabalho de parto e ou parto de sua companheira, internadas no CO, usuárias do Sistema Único de Saúde (SUS). Desses trabalhos de parto acompanhados, 13 tiveram como desfecho o parto vaginal e 11, a cesariana.

Foram incluídos os pais maiores de 18 anos, selecionados no $\mathrm{CO}$, após a leitura do prontuário da paciente, independente de ser ou não a primeira experiência como pai acompanhante, que 
o pré-natal da mulher fosse de baixo risco e que estiveram presentes durante o trabalho de parto e ou parto de sua companheira. Para continuarem no estudo, também foi necessário que o bebê tivesse nascido com idade gestacional igual ou superior a 37 semanas, com APGAR, avaliado no quinto minuto de vida, igual ou superior a sete e peso corporal adequado para sua idade gestacional.

Para o desenvolvimento do estudo seguimos as Diretrizes e Normas da Resolução n¹96/96 do Conselho Nacional de Saúde, ${ }^{14}$ e o projeto foi aprovado pelo Comitê de Ética e Pesquisa do HCPA - $\mathrm{n}^{\mathrm{o}}$ 09-025. O Termo de Consentimento Livre e Esclarecido foi assinado pelos participantes após serem informados sobre os objetivos do estudo e os critérios de inclusão para a coleta. Nele constou o destino das informações coletadas, assim como a autorização dos participantes para a publicação dos resultados. Aos acompanhantes e suas companheiras foi dada garantia de confidencialidade dos dados, anonimato e direito de desistir da participação em qualquer etapa do estudo. ${ }^{15} \mathrm{~A}$ companheira também assinou o Termo de Consentimento Livre e Esclarecido, devido a observação do casal, e a obtenção de dados do seu prontuário.

A coleta de dados realizada pela pesquisadora ocorreu no período entre março a agosto de 2009 por meio da observação participante e da entrevista semiestruturada. As observações participantes duravam aproximadamente uma hora, sendo realizadas previamente às entrevistas no $\mathrm{CO}$, com a finalidade de observar, nesse local, o pai como acompanhante da mulher no período de trabalho de parto ou parto. Durante a observação foram acompanhados alguns partos vaginais, o que não ocorreu com as cesarianas. Foram priorizadas as observações de parto normal uma vez que o foco da pesquisa foi o acompanhamento de parturientes de baixo risco. As entrevistas foram realizadas no dia seguinte, com uma flexível duração de tempo, em local cedido pela equipe de enfermagem, a fim de manter a privacidade e confidencialidade dos dados. Lá, o participante era informado sobre o início da entrevista que seria gravada em gravador digital (MP3).

Para esse estudo, o critério para o número de entrevistas esteve de acordo com o um número máximo de entrevistas que é necessário fazer e possíveis de serem analisadas, considerando que o limite para cada pesquisador está entre 15 a 25 entrevistas individuais. ${ }^{16}$

$\mathrm{Na}$ apresentação do tema e subtemas junto às falas dos participantes foi acrescentada a letra $\mathrm{E}$ para identificar os dados retirados via entrevista; a letra O sinaliza aqueles obtidos pela observação participante.

Os dados desse estudo foram analisados pelo método da análise de conteúdo do tipo temática, ${ }^{17}$ por possibilitar a descrição do conteúdo das mensagens. Para análise dos dados das entrevistas e observações participantes, estes foram organizados utilizando-se o software QSR NVivo, versão 7.0. Depois de organizados os dados e categorizadas as unidades de registros foram processadas as categorias intermediárias e, posteriormente, originou-se o tema que será apresentado a seguir

\section{RESULTADOS E DISCUSSÃO}

O tema aqui relatado será a experiência de ser acompanhante, que foi um dos temas, originados após a análise dos dados das entrevistas e dos registros da observação participante. Após a análise desse tema, emergiram dois subtemas: "A presença", relacionado com a percepção do pai quanto ao seu papel como acompanhante da mulher durante o processo de nascimento, e "O significado da experiência de vivenciar o nascimento do filho", referindo-se ao significado de ter sido acompanhante durante o processo de nascimento. ${ }^{18}$

\section{A experiência de ser acompanhante}

Ser acompanhante da mulher durante o trabalho de parto e parto representa para o homem uma oportunidade de vivenciar o nascimento de seu filho. Cada pai percebe sua participação como acompanhante de diversas maneiras. Independentemente de qual seja sua percepção desse papel, acredita-se que esse momento o remeta a uma experiência com um significado importante para sua vida.

Lembranças do nascimento do filho provavelmente permanecerão na sua memória para sempre. Talvez, para alguns pais, com maiores detalhes; para outros nem tanto. No entanto percebe-se que, de alguma forma, haverá um sentido único para cada pai que esteve presente no momento de a mulher dar a luz ao seu filho. Ser acompanhante da mulher durante o trabalho de parto e parto representa para o homem uma oportunidade de vivenciar o nascimento de seu filho.

São abordados como subtemas a presença e o significado da experiência de vivenciar o nascimento do filho. 


\section{A presença}

O suporte fornecido pelos pais à mulher, durante o processo de nascimento do seu filho envolveu, na prática, aspectos emocionais. Os pais perceberam que sua presença durante o trabalho de parto e parto foi a melhor forma de proporcionar apoio para ela. Estar presente nesse momento e poder acompanhar a evolução do trabalho de parto, assim como ajudar nas necessidades da mulher, parece ter sido fundamental para eles, conforme referem: [...] bom, eu acho que... ah, eu dei o apoio, né... mas no meu ver eu acho que eu podia ter dado para ela, entendeu, fiquei do lado dela, dando apoio (E1). Fiquei do lado dela todo o tempo, né [...] (E2).

Os pais verbalizaram também a preocupação com o fato de a mulher ficar sozinha. Acreditavam que, caso não estivessem presentes, isso poderia gerar nela um sentimento de abandono, de solidão, o que contribuiria de forma negativa no processo de nascimento e traria consequências, tanto para ela quanto para o bebê. Nesse sentido, eles referiram que sua presença poderia interferir de forma benéfica, nesse momento, para deixá-la mais calma e tranquila: [...] e ali tu te sente abandonado, é uma hora que tu te sente sozinho [...] então pelo menos alguém do lado, mesmo que não vá fazer nada, eu acho que aquele alguém te dá um pouquinho mais de coragem [...] ela precisa se sentir segura, senão, se ela não se sentir segura, se ela se sentir sozinha, pode dar outras complicações (E3).

Os dados de uma pesquisa realizada nesse mesmo hospital já apresentava essa preocupação dos pais acompanhantes com o sentimento de solidão que a mulher pudesse sentir durante o processo de nascimento. ${ }^{19}$ Em vista disso, essa preocupação já foi evidenciada em mulheres que, durante o trabalho de parto, solicitaram para não ficarem sozinhas por se sentirem mais calmas e seguras com a presença de alguém. $O$ fato de estarem só pode, inclusive, gerar medo. ${ }^{20}$

Durante as observações, percebeu-se que alguns pais permaneciam em silêncio na sala de pré-parto, ainda que a mulher, em trabalho de parto, referisse dor pelas contrações uterinas. Outros pais verbalizaram a preocupação em não atrapalhar o andamento do trabalho de parto de sua companheira, não realizando atividades que caberiam ao acompanhante. Ficavam num canto da sala, de onde pudessem olhar pela janela, mexendo em celulares: pai apóia a cabeça na mão, se ajeita na cadeira. Paciente de costa para o pai. Silêncio durante todo o tempo. Pai pega o celular, fica digitando no celular (O4). Paciente em trabalho de parto, e o pai, sentado, com fones de ouvidos, escutando música (O5). Um dos pais, ao ser entrevistado explicou que o fato de parecer alheio, ficando em silêncio, e não olhar para a parturiente, é por não saber o que fazer para ajudar, acreditando que o melhor é não atrapalhar: silêncio [...] então eu preferi ficar quieto, eu não queria ficar olhando, eu acho que a melhor ajuda foi não atrapalhar [...] (E3).

Nota-se a preocupação de alguns pais em não atrapalhar o andamento do trabalho de parto. $\mathrm{Na}$ percepção deles, sentiram-se acompanhantes da mulher, mesmo em silêncio, observando tudo o que estava acontecendo a sua volta, estando presentes, mas calados. Cabe, nesse momento, ressaltar que os pais desse estudo perceberam sua participação como acompanhante da mulher, durante o trabalho de parto ou no parto, de forma singular, única, o que parece significar que não existe um papel definido para o acompanhante de parto. Assim, independente das atividades exercidas ou não por eles, de fato, os pais entenderam-se como participantes desse processo.

Houve outros pais que se sentiram como cuidadores da mulher. Eles afirmaram que puderam auxiliar a equipe de saúde nos cuidados que estavam sendo prestados à mulher quando ela necessitava de algo: [...] eu participei em muitas coisas [...] na hora do banho [...] na salinha ali, pra gente [...] ela sentava na bola, essas coisas ali, para poder diminuir as contrações, ali a dilatação e tudo (E6).

Além da presença física junto à mulher, outra forma de participação, segundo os pais, foi conversar com ela. Sentiram que, ao verbalizar palavras de apoio e de carinho, tranquilizaram-na, amenizando o desconforto causado pelas contrações uterinas: [...] conversando com ela para ela não [...] para ela acalmar, não ficar nervosa [...] mas, no mais, ali eu fiz o que eu acho que estava no meu alcance, que eu pude passar de tranquilidade para ela (E1).

Há achados que indicam em relação a esse apoio emocional, que os pais que estabelecem uma boa relação verbal com a mulher, que dirigem a ela palavras de carinho, encorajamento e elogios, conseguem efetivamente acalmá-la. ${ }^{9}$ Esse apoio emocional também é enfatizada em outro estudo quando referem seus efeitos benéficos para a mulher, uma vez que elas relataram que o suporte dado pelo acompanhante, durante o trabalho de parto e parto, reforçou de forma positiva o processo de nascimento e propiciou segurança. ${ }^{21}$

Além desse apoio à mulher, os pais, quando observados, demonstraram uma relação de carinho e afeto para com ela. Tocavam, pegavam 
na mão, passavam durante o trabalho de parto, beijavam-na na barriga, no rosto, na boca, faziam carinho no rosto, na cabeça, colocavam a mão sobre a barriga para sentir o bebê se mexer, falavam palavras de conforto e de amor, estimulando a mulher, de certa forma, a permanecer mais segura e a se manter de forma positiva durante esse processo: o pai aproximou o seu rosto perto do rosto da paciente nos momentos de contração. Perguntou se ela queria se encostar nele, ela respondeu que sim, então ele levantou, se sentou na cama ao lado dela, e ela encostou o rosto no ombro dele. Ele fez carinho no rosto dela e massagens nas costas (O7).

Durante as observações de alguns partos, notou-se que os pais se sentiram valorizados em auxiliar a mulher no momento do nascimento do bebê. Com a chegada da proximidade do período expulsivo, alguns pais ficaram nervosos e tensos diante de um processo novo em suas vidas; outros, que já haviam presenciado o parto e até mesmo aqueles que estavam presentes pela primeira vez, foram, a cada instante, se tornando mais poderosos, intensificando o apoio emocional que davam à mulher, como se dependessem deles encorajá-la durante esse período. $\mathrm{O}$ apoio persistiu ao longo desse período, com palavras de incentivo, para que ela permanecesse com energia e força durante a contração uterina: o pai a ajuda, fala palavras de apoio, dizendo isso, 'só mais um pouco'. Num tom de voz baixo, o pai ajuda a segurar a cabeça da parturiente e fala para ela que falta pouco, para ela colocar o queixo no peito e fazer força. Nos intervalos das contrações ele acaricia o braço dela, falando palavras em tom baixo, ao pé do ouvido. No momento da contração, o pai olha para a parturiente, a chama de amor e pede para que ela faça novamente força, faz carinho no rosto dela, encosta o rosto dele no dela $(\mathrm{O} 8)$.

Percebeu-se o quanto foi importante para o pai estar presente durante esse momento e vivenciar ao seu lado o nascimento do seu filho, pois "[...] o pai vai encontrando o seu lugar junto à mulher e ao filho que está pra nascer. Ele passa a se perceber como um dos atores principais do evento, necessário para que tudo aconteça da melhor forma possível". 19:98

\section{O significado da experiência de vivenciar o nascimento do filho}

A presença do pai na cena do parto proporciona, tanto para ele quanto para a mulher, a vivência conjunta do nascimento do seu filho, passagem importante para a vida conjugal. ${ }^{22}$ Os pais, tanto aqueles que estavam vivenciando essa experiência pela primeira vez, quanto os que já haviam participado dela, verbalizaram que o nascimento de um filho é um momento único em suas vidas: [...] surpresa, né, mesmo já tendo [outro filho], parece que é o primeiro filho... como eu falei, né, parece que é, uma coisa única, assim.[...] (E9). Porque não tem muita experiência na nossa vida que seja igual a um parto [...] (E10).

Os pais trazem uma grande expectativa frente à cena do parto e estão carregados de intensas emoções e sentimentos, por isso perceberam que a experiência de ser acompanhante durante o parto é difícil de traduzir em palavras, são momentos inexplicáveis: [...] olha, assim, foi uma coisa sem palavras, porque... sensacional, assim, uma experiência inédita, só quem passa por isso para saber como é que é, é uma coisa linda (E11).

Atualmente, percebe-se que há mais interesse dos pais em acompanhar o processo de nascimento do filho, embora alguns homens talvez achem cansativa a experiência de participar do parto, enquanto outros a considerem até mesmo divertida, recordando-a com grande satisfação, mesmo que a ansiedade frente à dor da mulher possa lhes parecer como impotência. ${ }^{23}$

Assim, no presente estudo, alguns participantes reforçaram a idéia de que houve satisfação na vivência dessa experiência, mesmo com momentos de impotência diante do processo: [...] significou uma coisa que eu nunca havia sentido antes, senti um estado de impotência e potência ao mesmo tempo, senti a pessoa mais realizada do mundo (E8).

$\mathrm{O}$ apoio dado à mulher pode trazer como consequência o fortalecimento da relação do casal. ${ }^{24}$ No presente estudo, principalmente no período do trabalho de parto, os pais perceberam o quanto gostavam da sua companheira, valorizando cada instante em que estiveram juntos. Eles vivenciaram e experimentaram um sentimento de preocupação com o bem-estar dela: [...] eu percebi o quanto eu gosto dela (E8).

Em suas falas, os pais reafirmaram o quanto foi importante estarem presentes nos primeiros minutos de vida do seu filho, sentindo-se gratificados ao serem os primeiros a pegar o bebê no colo e poder ouvir o choro. É possível perceber a emoção do pai pelo nascimento do filho, demonstrando que já existe um envolvimento emocional a partir dos primeiros momentos de vida do bebê fora do útero materno, o que evidencia o vínculo entre pai e filho: [...] os primeiros segundos da vida de um nenê saindo... o fato dele sair e ir pra cima da mãe, depois 
tu acompanhar a limpeza dele, depois segurar ele, ser o primeiro a segurar ele [...] (E10).

Nesse momento, a interação entre pai e filho se torna essencialmente palpável, enquanto que, na gestação, era preferencialmente da mulher. ${ }^{24}$ Verifica-se assim o quanto é importante para o homem vivenciar o nascimento do seu filho, um momento que faz parte da transição para o papel de pai ao poder concretizar a espera de aproximadamente nove meses e ver o bebê, pegá-lo nos braços.

Foi constatado também que os pais, estando presentes na cena do parto, ficaram tranquilos, podendo ver que tudo deu certo, que a mulher estava bem, que o bebê nasceu bem, que o parto transcorreu como deveria. Além disso, foi-lhes possível acompanhar as ações médicas e verificar se tudo estava ocorrendo com normalidade, como afirma: [...] ah, é gratificante [...] gratificante poder ver que saiu tudo bem, poder acompanhar o trabalho do médico, foi muito bom [...] (E4).

Quanto ao significado dessa experiência, alguns pais informaram sua apreensão sobre se conseguiriam ou não permanecer na sala durante o parto, mas, ao vivenciarem o nascimento, perceberam que esse momento pode ser calmo, tranquilo e que é possível acompanhá-lo, como se verificou na seguinte fala: [...] ah, eu achei que seria uma coisa assim meio de provar que eu conseguiria, mas foi tranquilo assim, eu achei até que ia ser mais... porque eu tenho medo de agulha, essas coisas, medo de sangue, mas eu fui... foi tranquilo (E4).

Ao acompanharem o parto, alguns pais mudam sua ideia a respeito da sala cirúrgica. Eles imaginavam a sala agitada, com presença de sangue e agulhas. Assim, ao entrar na sala de parto, esperam um ambiente diferente do que encontram, percebendo então, que não é como haviam imaginado. Quando verificam como é o ambiente hospitalar, eles desmitificam todo o processo. ${ }^{25}$

Independente disso, para os pais do presente estudo, a experiência de acompanhar o parto foi tão gratificante que pretendem recomendá-la a outros pais. Eles entenderam que esta é uma obrigação deles, acompanhar a mulher durante o processo de nascimento, e que essa participação proporciona segurança e apoio à parturiente evitando possíveis complicações, conforme afirma: [...] gostei. Achei muito importante... não achei tão importante, acho queé um dever de todo mundo. Até mesmo porque já dá aquela segurança pra gestante [...] (E3).

Por outro lado, apenas um pai referiu sentir-se traumatizado com a experiência, possivelmente pelo fato de estar pouco informado acerca do processo de nascimento, referindo, inclusive, que gostaria de ter o direito de não acompanhar o trabalho de parto, caso venha a ter outros filhos: [...] eu senti um sentimento de trauma... fiquei pensando assim, bah, que loucura... sabe, o que que é isso... eu não sabia, eu não tinha ideia o que era isso, olha, se ela quisesse, eu iria de novo ver ela, mas se eu pudesse ter a escolha de não ficar no pré-parto, eu não ficava... eu não sabia o que fazer, eu fiquei mais nervoso que ela... do parto tudo bem, mas o pré-parto não (E12).

Pela fala acima, pode-se deduzir o despreparo do pai para participar como acompanhante no período de trabalho de parto da sua companheira. Durante as observações, muitas vezes foi constatada a surpresa da maioria dos pais pela oportunidade de acompanhar o parto da mulher. Na sua maioria, os pais resolveram ser acompanhantes da mulher no momento da internação hospitalar, não tendo conhecimento da Lei do Acompanhante. Nesse sentido alerta-se para que essa decisão deve ser tomada conscientemente, em conjunto pelo casal preferencialmente no período gestacional. Aos profissionais da saúde, cabe convidar o pai a participar e não impor que seja acompanhante, se esta não for sua vontade.

Importante também destacar que, em um estudo realizado com pais durante a gestação, foi constatado que, embora estivessem preocupados em participar das consultas de pré-natal, das ecografias, do preparo familiar para a chegada do bebê e com o bem-estar de sua companheira, poucos foram aqueles que verbalizaram a vontade de acompanhar o parto, indicando, assim, a representação essencialmente feminina do parto. ${ }^{1}$

É preciso, portanto, que a equipe de saúde que está assistindo esse casal identifique possíveis momentos de extrema tensão tanto do homem quanto da mulher, assim como auxilie o pai no sentido de esclarecer suas dúvidas e de informar as ações que ele poderá realizar com a mulher durante o trabalho de parto para que essa não se torne uma experiência negativa em sua vida.

\section{CONSIDERAÇÕES FINAIS}

O estudo indicou que, mesmo não realizando as atividades pertinentes ao acompanhante do parto e, muitas vezes, permanecendo em silêncio, alguns pais consideraram sua presença importante em todo o processo de parturição, por poderem oferecer apoio emocional à mulher, dando-lhe segurança através de palavras, gestos de carinho e conforto; também se sentiram acompanhantes 
da mulher nos momentos de espera ao lado dela, proporcionando-lhe companhia e acalmando-a no momento das contrações uterinas.

Observou-se, inclusive, que estar presente durante esse processo permitiu para alguns pais uma transição tranquila para a parentalidade. Isto se deu também quando eles puderam pegar o bebê no colo, ouvir seu choro, ver que tudo tinha dado certo.

Nesse sentido, o estudo destaca o valor que tem para o pai a possibilidade de vivenciar o nascimento do seu filho, seja pela primeira vez ou não. Essa vivência reveste-se de especial importância na sua participação em todas as etapas do ciclo gravídico-puerperal, o que é fundamental para a formação do vínculo pai-filho.

Percebeu-se, no entanto, através das falas dos participantes, que, embora eles tivessem o desejo de poder ver seu filho nascer, para a maioria, a possibilidade de realização dessa vontade pegou-os de surpresa no ato da internação hospitalar, e isso trouxe consigo todas as implicações de uma decisão tomada sem a devida preparação.

O presente estudo alerta para a necessidade de informar ao pai a possibilidade dele acompanhar a mulher durante o trabalho de parto e parto, e para a importância de prepará-lo, ao longo do período gestacional, durante as consultas de pré-natal, em conjunto com a mulher. Esse alerta se deve à constatação desse estudo de que a experiência de vivenciar o processo de nascimento pode se tornar uma lembrança traumática para o pai quando este não se encontra em condições para tal.

\section{REFERÊNCIAS}

1. Piccinini CA, Silva MR, Gonçalves TR, Lopes RS, Tudge J. O envolvimento paterno durante a gestação. Psicol. Reflex. Crít. 2004 Set-Dez; 17(3):303-14.

2. Maldonado MTP. Nós estamos grávidos. $10^{a}$ ed. São Paulo (SP): Saraiva; 1997.

3. Brasil. Lei No 11.108, de 7 de abril de 2005. Dispõe sobre a garantia às parturientes o direito à presença de acompanhante durante o trabalho de parto, parto e pós parto imediato, no âmbito do Sistema Único de Saúde - SUS. Diário Oficial da República Federativa do Brasil, 8 abril 2005. Seção 1.

4. Storti JPL. O papel do acompanhante no trabalho de parto e parto: expectativas e vivências do casal [dissertação]. São Paulo (SP): Universidade de São Paulo. Programa de Pós Graduação em Enfermagem; 2004

5. Domingues RMSM. Acompanhantes familiares na assistência ao parto normal: a experiência da maternidade Leila Diniz [dissertação]. Rio de Janeiro (RJ): Escola Nacional de Saúde Pública, Fundação Oswaldo Cruz; 2002.

6. Brüggemann OM, Parpinelli MA, Osis MJD. Apoio no nascimento: percepções de profissionais e acompanhantes escolhidos pela mulher. Rev Saúde Pública. 2007 Fev; 41(1):44-52.

7. Domingues RMSM, Santos EM, Leal MC. Aspectos da satisfação das mulheres com a assistência ao parto: contribuição para o debate. Cad Saúde Pública. 2004 20(Sup 1):552-62.

8. Brüggemann OM, Parpinelli MA, Osis MJD, Cecatti JG, Neto ASC. Support to woman by companion of her choice during chilbirth: a randomized controlled trial. Reprod Health [online]. 2007 [acesso 2008 Ago 20]; 4(5):1-7. Disponível em: http:/ / www. reproductive-health-journal.com/content/4/1/5

9. Motta CCL, Crepaldi MA. O pai no parto e apoio emocional. Paidéia [online]. 2005 [acesso 2009 Mar 14]; 15(30). Disponível em: http:/ / sites.ffclrp.usp. br/paideia/artigos/30/11.htm

10. Freitas WMF, Coelho EAC, Silva ATMC. Sentir-se pai: a vivência masculina sob o olhar de gênero. Cad Saúde Pública. 2007 Jan; 23(1):137-45.

11. Tarnowski KS, Próspero ENS, Elsen I. A participação paterna no processo de humanização do nascimento: uma questão a ser repensada. Texto Contexto Enferm. 2005 Jul; 14(Esp):102-8.

12. Minayo MCS. Pesquisa social: teoria, método e criatividade. Petrópolis (RJ): Vozes; 1994.

13. Stake R. Investigación com studio de casos. Madrid (ES): Ediciones Morata, S.L; 1998.

14. Ministério da Saúde (BR). Conselho Nacional de Saúde. Resolução n ${ }^{\circ} 196$ de 10 de outubro de 1996: diretrizes e normas regulamentadoras de pesquisas envolvendo seres humanos. Brasília (DF): MS; 1996.

15. Goldim JR. Manual de iniciação à pesquisa em saúde. Porto Alegre (RS): Dacasa;1997.

16. Bauer MW, Gaskell G. Pesquisa qualitativa com texto, imagem e som: um manual prático. Petrópolis (RJ): Vozes; 2002.

17. Bardin L. Análise de conteúdo. $3^{\mathrm{a}}$ ed. Lisboa (PT): Edições 70; 2004.

18. Perdomini FRI. A participação do pai como acompanhante de mulher no processo de nascimento [dissertação]. Porto Alegre (RS): Universidade Federal do Rio Grande do Sul. Programa de Pós Graduação em Enfermagem; 2010.

19. Espírito Santo LC. O desejado e o vivido pelo pai durante o processo de parto e nascimento de seu bebê [dissertação]. Porto Alegre (RS): Universidade Federal do Rio Grande do Sul. Programa de Pós Graduação em Enfermagem; 2000.

20. Rodrigues AV, Siqueira AAF. Sobre as dores e temores do parto: dimensões de uma escuta. Rev. Bras. Saúde Mater. Infant. 2008 Abr- Jun; 8(2):179-86. 
21. Silva AVR, Siqueira AAR. O valor do suporte a paciente: um estudo de relação interpessoal no contexto de um centro de parto normal. Rev Bras Crescimento Desenvol Hum. 2007 Abr; 17(1):126-35.

22. Carvalho MLM. Participação dos pais no nascimento em maternidade pública: dificuldades institucionais e motivações dos casais. Cad Saúde Pública. 2003; 19(Sup. 2):389-98.

23. Raphael-leff J. Gravidez: a história interior. Porto Alegre (RS): Artes Médicas; 1997.
24. Guzzo GM. Conhecendo os pais que acompanham o nascimento dos seus filhos: quem são e o que pensam sobre sua participação no parto [trabalho de conclusão]. Porto Alegre (RS): Universidade do Rio Grande do Sul; 2008.

25. Tomeleri KR. Pieri FM, Violin MR, Serafim D, Marcon SS. Eu vi o meu filho nascer: vivência dos pais na sala de parto. Rev Gaúcha Enferm. 2007 Dez; 28(4):497-504. 